Cecilia Gómez Ravetti ${ }^{1}$, Tatiana Oliveira Silva ${ }^{2}$, Anselmo Dornas Moura $^{3}$, Frederico Bruzzi de Carvalho ${ }^{4}$

1. Mestre, Médica do Centro de Terapia Intensiva do Hospital Mater Dei - Belo Horizonte (MG), Brasil.

2. Médica do Centro de Terapia Intensiva do Hospital Mater Dei, Belo Horizonte (MG), Brasil.

3. Médico do Centro de Terapia Intensiva do Hospital Mater Dei - Belo Horizonte (MG), Brasil.

4. Médico do Centro de Terapia Intensiva do Hospital Mater Dei - Belo Horizonte (MG), Brasil.

Recebido do Centro de Terapia Intensiva do Hospital Mater Dei - Belo Horizonte (MG), Brasil.

Submetido em 20 de Julho de 2009

Aceito em 9 de Dezembro de 2009

Autor para correspondência:

Cecilia Gómez Ravetti

Rua Sagitário 320, apt. 01

CEP: 30360-230 - Belo Horizonte

(MG), Brasil.

Fones: (31) 3024-9413 - (31) 9959-6555

E-mail: ceciliag.ravetti@gmail.com

\section{Estudo de pacientes reanimados pós-parada cardiorrespiratória intra e extra-hospitalar submetidos à hipotermia terapêutica}

\author{
Study of resuscitated in-and out-hospital cardiorespiratory arrest \\ patients undergoing therapeutic hypothermia
}

\section{RESUMO}

Objetivo: Conhecer as características dos pacientes submetidos a um protocolo operacional padrão institucional de atendimento a pacientes reanimados após episódio de parada cardiorrespiratória incluindo a aplicação de hipotermia terapêutica.

Métodos: Foram analisados retrospectivamente 26 pacientes consecutivos após episódio de parada cardiorrespiratória de janeiro de 2007 a novembro de 2008.

Resultados: Todos os casos foram submetidos a hipotermia terapêutica. Idade média de 63 anos, predominantemente do sexo masculino. O local da parada cardiorrespiratória foi extra-hospitalar em 8 casos, pronto socorro em 3, durante internação fora da unidade de terapia intensiva em 13 casos e o bloco cirúrgico em 2 casos. $\mathrm{O}$ ritmo de parada foi fibrilação ventricular em sete pacientes, assistolia em 11, atividade elétrica sem pulso em 5 casos e não foi determinado em 3 pacientes. $\mathrm{O}$ intervalo entre a parada e o retorno à circulaçáo espontânea foi de $12 \pm 5$ minutos. O tempo reque- rido para alcançar a temperatura alvo foi de 5 \pm 4 horas, o tempo de hipotermia foi de 22 \pm 6 horas e para o reaquecimento usaram-se $9 \pm 5,9$ horas. Catorze pacientes evoluíram a óbito na unidade de terapia intensiva, representando uma mortalidade de $54 \%$, e três pacientes tiveram o mesmo desfecho durante a internação, determinando uma mortalidade intra-hospitalar de 66\%. Houve redução estatisticamente significativa dos valores de hemoglobina $(\mathrm{p}<0,001)$, leucócitos $(\mathrm{p}=0,001)$, plaquetas $(\mathrm{p}<0,001)$, lactato $(\mathrm{p}<0,001)$ e potássio $(\mathrm{p}=0,009)$, e aumento de proteína $C$ reativa $(p=0,001)$ e $R N I(p=0,004)$ após aplicação de hipotermia.

Conclusóes: A elaboração de protocolo operacional padrão de hipotermia terapêutica para o tratamento de pacientes com parada cardiorrespiratória, utilizandose das rotinas adaptadas de estudos randomizados, resultou em elevada aderência e seus resultados assemelham-se aos dados publicados na literatura.

Descritores: Hipotermia; Parada cardíaca; Cuidados intensivos

\section{INTRODUÇÃO}

A parada cardiorrespiratória (PCR) é a causa mais freqüente de isquemia global cerebral. Acomete entre 400000 e 460000 pessoas por ano nos Estados Unidos. ${ }^{(1)}$ Entre 7 e 10\% dos pacientes que são inicialmente ressuscitados após PCR extrahospitalar de causa cardíaca sobrevivem e recebem alta hospitalar com bom resultado neurológico ${ }^{(2)}$ e $18 \%$ após PCR intra-hospitalar. ${ }^{(3)}$

O retorno à circulação espontânea (ROSC) após um episódio PCR leva à síndrome de pós-parada cardiorrespiratória. Apesar dos avanços nas terapias disponíveis para o tratamento da PCR, nos últimos 50 anos houve poucas mudanças no prognóstico dos pacientes que sobrevivem a este evento. A mortalidade destes pacientes, em trabalho publicado em 1953 era de 50\%, ${ }^{(4)}$ e em 2006, o National Re- 
gistry of Cardiopulmonary Ressucitation, após análise de mais de 19000 adultos e 500 crianças, mostrou mortalidade de 67 e $55 \%$ respectivamente. ${ }^{(4)}$

Os cuidados pós PCR podem reduzir a mortalidade precoce devido à instabilidade hemodinâmica e disfunção orgânica múltipla, e a tardia devido ao dano cerebral. ${ }^{(5)}$ A maioria das mortes pós PCR ocorrem nas primeiras 24 horas de ROSC. $^{(6)}$

A síndrome pós-parada cardiorrespiratória caracterizase pelo comprometimento dos sistemas cardiovascular, neurológico, pulmonar, renal e metabólico. ${ }^{(7)} \mathrm{Em}$ dois estudos prospectivos, controlados e randomizados, realizados na Austrália ${ }^{(8)}$ e Europa, ${ }^{(9)}$ observou-se benefício na indução de hipotermia durante 12 e 24 horas, respectivamente, em pacientes que permaneceram em coma após retorno a circulação espontânea. Nestes estudos, publicados em 2002, foi comparada a indução de hipotermia com normotermia pós PCR.

Baseado nesta evidência, a International Liaison Commitee on Resuscitation (ILCOR), inclui este tratamento nas recomendaçôes para os pacientes em pós parada cardiorrespiratória, incluindo pacientes com retorno à circulação espontânea pós PCR fora de hospitais, durante 12 a $24 \mathrm{~h}$, quando o ritmo de parada fosse fibrilação ventricular (FV). Apesar de não existir evidência até o momento, incluiu, também, pacientes com outros ritmos de parada e aquelas ocorridas dentro de ambiente hospitalar. ${ }^{(10)}$

O mecanismo pelo qual a hipotermia produz benefício não é totalmente conhecido. Em cérebros normais, diminui o consumo de oxigênio em $6 \%$ a cada reduçáo em $1{ }^{\circ} \mathrm{C}$ acima de $28^{\circ} \mathrm{C}$. Reduz reaçóes químicas associadas com a reperfusão, tais como a produção de radicais livres de oxigênio, liberação de aminoácidos excitatórios e o intercâmbio do cálcio que levam ao dano mitocondrial e apoptose. ${ }^{(10)}$

Porém, apesar da hipotermia ser uma terapêutica recomendada neste grupo de pacientes, não é uma medida amplamente usada em nosso meio. Durante os meses de janeiro e fevereiro de 2007 foi elaborado e divulgado um procedimento operacional padrão (POP) para guiar o atendimento, aumentar a aderência ao tratamento e reduzir a variabilidade da aplicaçáo desta modalidade terapêutica no Hospital Mater Dei em Belo Horizonte, MG. O objetivo do presente estudo foi conhecer os resultados obtidos após a introdução de protocolo de hipotermia terapêutica em pacientes vítimas de parada cardiorrespiratória fora da unidade de terapia intensiva (UTI). Além disso, determinar a interveniência de fatores como tempo de hipotermia, tempo para atingir hipotermia, tempo de reaquecimento e dados laboratoriais no desfecho de pacientes submetidos a hipotermia terapêutica.

\section{MÉTODOS}

Com o intuito de conhecer a epidemiologia e os resultados no atendimento de pacientes vítimas de parada cardiorrespiratória, foram analisados retrospectivamente todos os pacientes admitidos pós PCR em qualquer ritmo fora da UTI, que permaneceram em coma após o retorno a circulação espontânea e que foram submetidos a tratamento com hipotermia, de janeiro de 2007 a novembro de 2008, na UTI do Hospital Mater Dei - Belo Horizonte (MG).

Os pacientes foram abordados segundo o protocolo de hipotermia adotado no serviço. Para a coleta dos dados foi usada a base de dados da UTI-Hospital Mater Dei. Este trabalho foi aprovado pelo comitê de Ética em Pesquisa do hospital.

\section{Protocolo}

O protocolo seguiu as diretrizes do POP-M-UTI-032, discutido em janeiro de 2007, publicado em fevereiro de 2007..$^{(11)}$

Para evitar demoras no início da terapêutica, o leito foi previamente preparado com colchão térmico com sensor de temperatura esofágica para receber o paciente. Todos os pacientes foram submetidos à reanimação inicial visando corrigir agressivamente hipotensão, hipovolemia, hipoxemia e hipoglicemia. Iniciou-se sedação contínua com midazolam e fentanil e curarização em infusão contínua com cisatracúrio ou em bolus com pancurônio. Os pacientes com indicação de cineangiocoronariografia foram imediatamente submetidos a este procedimento.

O objetivo da temperatura foi de 32 a $34^{\circ} \mathrm{C}$, alcançada com a infusão de $30 \mathrm{ml} / \mathrm{kg}$ de $\mathrm{NaCl} 0,9 \%$ ou ringer lactato a 4 a $8^{\circ} \mathrm{C},{ }^{(12)}$ aplicação de gelo em dobras cutâneas e utilização de colchão térmico até atingir a temperatura alvo. Caso a temperatura não tivesse sido alcançada, repetia-se infusão intravenosa de solução cristalóide gelada em $4 \mathrm{~h}$.

Os pacientes foram monitorados com pressão arterial invasiva para manuseio hemodinâmico e coleta seriada de exames (gasometria arterial, lactato, coagulograma, hemograma completo, íons). Foi implantado cateter venoso central para realização de provas volêmicas e administração de vasopressores e inotrópicos, se necessário. A monitorizaçáo com cateter de Swan Ganz foi realizada segundo critério do médico intensivista.

Foi realizado ecocardiograma transtorácico e feita revisão laboratorial dos exames anteriormente citados em todos os pacientes. A temperatura foi mantida no objetivo num período de 12 a $24 \mathrm{~h}$. 
$\mathrm{O}$ reaquecimento foi iniciado com o reajuste da temperatura do colchão térmico em $0,5^{\circ} \mathrm{C}$ por hora até atingir os $36^{\circ} \mathrm{C}$. Os bloqueadores neuromusculares foram mantidos durante o reaquecimento e administrados antitérmicos profiláticos por $48 \mathrm{~h}$.

\section{Análise estatística}

Foi realizada análise descritiva de todas as variáveis. Variáveis contínuas foram expressas como média \pm desvio padrão e mediana (mínimo - máximo). A normalidade foi verificada através do teste de Shapiro-Wilk. Para a comparação de médias no caso de variáveis independentes e normais foi utilizado o teste $t$ Student para amostras independentes. No caso de não normalidade foi realizada comparação de medianas por meio do teste de Mann-Whitney. $\mathrm{Na}$ comparaçáo de mais de dois grupos pareados, foi utilizada a análise de variância (ANOVA) para medidas repetidas no caso de normalidade e o teste de Friedmann no caso de não normalidade. Para localizar as diferenças detectadas na ANOVA aplicou-se o teste de comparaçóes múltiplas de Tukey. No teste de Friedmann foi utilizado o teste de Dunn para as comparaçóes múltiplas. O nível de significância foi de 0,05 .

Devido ao pequeno tamanho de amostra, a variável 'desfecho' foi recodificada e se transformou em dicotômica, sendo uma categoria não sobreviventes e outra sobreviventes.

Os pacotes estatísticos utilizados na análise foram GraphPad Prism 4 for Windows e SPSS 12.0 for Windows.

\section{RESULTADOS}

Foram estudados 26 pacientes internados de janeiro de 2007 a novembro de 2008 com episódio de parada cardíaca (PCR) na UTI do Hospital Mater Dei. Os pacientes tinham em média 63,0 $\pm 18,0$ anos, e mediana de 64,5 (19-91) anos. O sexo masculino foi o predominante, representando $92,3 \%$ dos casos. O local da parada cardiorrespiratória foi extra-hospitalar em 8 casos, no pronto socorro em 3 casos, durante internaçáo no hospital fora do UTI em 13 casos e no bloco cirúrgico em 2 casos. O ritmo de parada cardiorrespiratória encontrado foi fibrilação ventricular em 7 pacientes, assistolia em 11, atividade elétrica sem pulso (AESP) em 5 pacientes e o ritmo não foi determinado em 3 pacientes. $\mathrm{O}$ intervalo entre a parada cardiorrespiratória e o retorno à circulação espontânea foi, em média, 12,0 \pm 5,0 minutos. $\mathrm{O}$ tempo requerido para alcançar a temperatura alvo desde a admissáo foi, em média, 5,0 \pm 4,0 horas. O tempo de hipotermia foi em média 22,0 $\pm 6,0$ horas. Para o reaquecimento usaram-se
$9,0 \pm 5,9$ horas. O lactato à admissão foi em média 6,0 $\pm 3,7$. O glicemia ficou, em média, em 133,0 $\pm 17,0 \mathrm{mg} /$ dL. (Tabela 1).

Tabela 1 - Distribuiçáo do local e ritmo de parada encontrado em pacientes pós parada cardiorrespiratória

\begin{tabular}{lcc}
\hline & $\mathrm{N}$ & $\%$ \\
\hline Local da PCR & & \\
Enfermaria/Apto & 13 & 50 \\
Bloco cirúrgico & 2 & 8 \\
Extra-hospitalar & 8 & 31 \\
Pronto socorro & 3 & 12 \\
Total & 26 & 100 \\
Ritmo parada & & \\
AESP & 5 & 19 \\
Assistolia & 11 & 42 \\
FV & 7 & 27 \\
Desconhecido & 3 & 12 \\
Total & 26 & 100 \\
\hline
\end{tabular}

PCR - parada cardiorrespiratória; AESP - atividade elétrica sem pulso; FV - fibrilação ventricular.

O resultado obtido após aplicação de hipotermia mostra-se na tabela 2. Nove pacientes tiveram alta do UTI e, destes, cinco tiveram alta hospitalar, dois foram transferidos a outras instituiçóes e dois permanecem internados no apartamento. Catorze pacientes evoluíram a óbito no UTI, representando uma mortalidade de 54\% intra UTI, e três pacientes tiveram o mesmo desfecho durante internação no andar, representando uma mortalidade intrahospitalar de 66\%.

Tabela 2 - Distribuiçáo do desfecho

\begin{tabular}{lcc}
\hline Desfecho & $\mathrm{N}$ & $\%$ \\
\hline Alta UTI/Hospital & 5 & 19 \\
Alta UTI/Transferência & 2 & 8 \\
Alta UTI/Internado andar & 2 & 8 \\
Óbito UTI & 14 & 54 \\
Óbito fora do UTI & 3 & 12 \\
Total & 26 & 100 \\
\hline UTl
\end{tabular}

UTI - unidade de terapia intensiva.

O ritmo de parada variou entre os sobreviventes. Nos pacientes que receberam alta do UTI, o ritmo de PCR encontrado foi $\mathrm{FV}$ em 5 pacientes, assistolia em 2 pacientes, AESP em 1 e desconhecido em 2 pacientes. O lugar da PCR entre os sobreviventes ficou assim distribuído: 3 no apartamento, 1 no pronto socorro, 3 foram extra-hospitalares e 2 no bloco cirúrgico. 
Tabela 3 - Horas até hipotermia, tempo em hipotermia e tempo para reaquecimento em funçáo do desfecho

\begin{tabular}{llccccc}
\hline Variável & Desfecho & $\mathrm{N}$ & Média \pm DP & Mediana (Min-Max) & Estatística & Valor de p \\
\hline Intervalo entre PCR até hipo- & Sobreviventes & 9 & & $9(5-12)$ & $24,5^{*}$ & 0,005 \\
termia (horas) & Náo sobreviventes & 17 & & $4(0,5-6)$ & & \\
Tempo em hipotermia (horas) & Sobreviventes & 9 & $20.4 \pm 2,9$ & & $-1,2^{* *}$ & 0,235 \\
& Não sobreviventes & 17 & $23.4 \pm 6,9$ & & & \\
\multirow{2}{*}{$\begin{array}{l}\text { Tempo até reaquecimento } \\
\text { (horas) }\end{array}$} & Sobreviventes & 9 & & $5(4-12)$ & $53,5^{*}$ & 0,291 \\
\hline
\end{tabular}

PCR - parada cardiorespiratória; DP - desvio padrão; Min-Max - mínimo-máximo. *Estatística U de Mann-Whitney para comparação de medianas devido a distribuição não paramétrica.. ${ }^{* *}$ Teste $t$ Student para comparação de médias devido a distribuição normal.

Tabela 4 - Perfil laboratorial em funçáo do momento: à admissáo, durante hipotermia e após reaquecimento

\begin{tabular}{lcccc}
\hline Variável & Admissáo & Durante hipotermia & Após reaquecimento (48 horas) & Valor de p \\
\hline Hemoglobina & $11,7 \pm 3,2(26)$ & $11,5 \pm 3,0(26)$ & $10,6 \pm 2,4(26)$ & $<0,001 \#^{*}$ \\
PCR & $38,5(8,5-145,3)(22)$ & $83,0(43-152)(24)$ & $151,0(105,5-204,5)(25)$ & $0,001 \&^{*}$ \\
Leucócitos & $15,8(12,3-21,2)(24)$ & $10,9(8,4-15,7)(26)$ & $10,0(8,7-13.2)(25)$ & $0,001 \&^{*}$ \\
Plaquetas & $210,1 \pm 78,1(25)$ & $162,7 \pm 72,9(26)$ & $145,5 \pm 69,9(25)$ & $<0,001 \#^{*}$ \\
Creatinina & $1,7 \pm 1,7(25)$ & $1,3 \pm 0,9(25)$ & $1,3 \pm 0,8(25)$ & $0,317 \#$ \\
Potassio & $4,1 \pm 1,1(26)$ & $3,5 \pm 0,7(25)$ & $4,0 \pm 0,8(26)$ & $0,009 \#^{*}$ \\
$\mathrm{SvO}_{2}$ & $73 \pm 12,8(10)$ & $75,8 \pm 10,1(18)$ & $73,7 \pm 10,1(16)$ & $0,655 \#$ \\
$\mathrm{Lactato}$ & $6,2 \pm 3,7(26)$ & $3,0 \pm 3,4(24)$ & $1,9 \pm 1,3(24)$ & $<0,001 \#^{*}$ \\
\hline
\end{tabular}

PCR - proteína $\mathrm{C}$ reativa; $\mathrm{SvO}_{2}$ - saturação venosa de oxigênio. Resultados expressos em média \pm desvio padrão ou mediana (min-max). Entre parênteses, número de pacientes em que o exame foi obtido.Utilizado teste de Friedman para variáveis com distribuição assimétrica.

\# Teste ANOVA para variáveis com distribuição normal.

* estatisticamente significativo.

Após análise das variáveis horas até hipotermia, tempo em hipotermia e tempo para o reaquecimento em função do desfecho (dicotômico), observou-se que existe diferença significativa das medianas de horas até a hipotermia em função do desfecho. Os pacientes que sobreviveram têm mediana maior 9 (5-12) do que quem evolui a óbito $(\mathrm{p}=0,005)$ (Tabela 3). Para o tempo em hipotermia e tempo para reaquecimento não foram detectadas diferenças significativas.

Enquanto às variáveis hemodinâmicas analisadas, em média, os pacientes usaram $0,47 \pm 0,90 \mathrm{mcg} / \mathrm{kg} / \mathrm{min}$ de noradrenalina, sendo que durante o período fora da hipotermia, esse valor foi de $0,33 \pm 0,21 \mathrm{mcg} / \mathrm{kg} / \mathrm{min}$, enquanto durante o tempo de hipotermia, esse requerimento foi de $0,47 \pm 0,26 \mathrm{mcg} / \mathrm{kg} / \mathrm{min}$. A pressão arterial média encontrada durante a hipotermia foi de $87,0 \pm 4,3 \mathrm{mmHg}$, e fora deste período de $83,0 \pm 6,8 \mathrm{mmHg}$. A freqüência cardíaca teve, durante a hipotermia, uma média de 79,0 \pm $5,0 \mathrm{bpm}$, e fora deste período, de 87,0 \pm 4,0 bpm. A média observada no débito cardíaco durante hipotermia foi de $2,70 \pm 0,44 \mathrm{~L} / \mathrm{min}$, enquanto que fora deste período foi de $3,20 \pm 0,66 \mathrm{~L} / \mathrm{min}$.

Somente dois pacientes usaram vasopressina $(7,7 \%)$. Em quinze pacientes foi usada dobutamina (58\%). A mo- nitoração com cateter em artéria pulmonar foi utilizada em 14 pacientes (54\%). A glicemia média encontrada foi em média de $133 \mathrm{mg} / \mathrm{dl}(\mathrm{DP} \pm 17)$.

Foram analisados dados laboratoriais tais como hemoglobina, leucócitos, plaquetas, proteína $\mathrm{C}$ reativa, relação normatizada internacional (RNI), creatinina, lactato, potássio, $\mathrm{pH}$, bicarbonato e Sv02 na hora zero, durante hipotermia (24hs) e às 48 hs para observar alterações relacionadas com o a indução deste tratamento. $\mathrm{Na}$ tabela 4 apresenta-se a distribuição dos valores encontrados para cada variável. Foi detectada diferença significativa das médias em função do momento para as variáveis hemoglobina, proteína $\mathrm{C}$ reativa, leucócitos, plaquetas, $\mathrm{RNI}$, potassio e lactato.

Para a variável hemoglobina e leucócitos houve queda, estatisticamente significativa, após aplicação de hipotermia ( $<<0,001$ e 0,001 respectivamente). Para a variável proteína $\mathrm{C}$ reativa notou-se aumento da mesma após reaquecimento $(\mathrm{p}=0,001)$. Houve queda estatisticamente significativa das médias de plaquetas $(\mathrm{p}<0,001)$, lactato $(\mathrm{p}<0,001)$ e potássio $(\mathrm{p}=0,009)$, e alargamento de RNI $(\mathrm{p}=0,004)$. Para uma melhor ilustração das diferenças detectadas, foram feitos Box-plots destas variáveis em função do momento (Figura 1). 

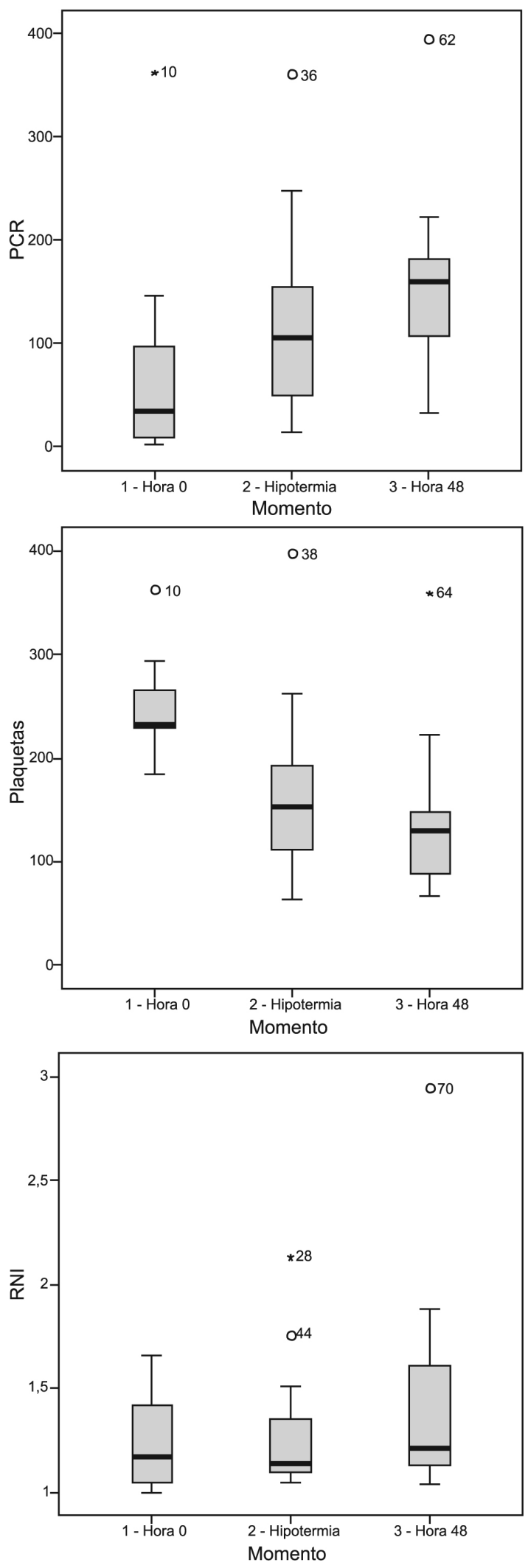

PCR - proteína C reativa; RNI - relação normatizada internacional.

Figura 1 - Dados laboratoriais em funçáo do tempo (admissáo, hipotermia e após 48 horas).

\section{DISCUSSÁO}

A mortalidade dos pacientes vítimas de PCR permanece em níveis muito elevados. ${ }^{(1)}$ Em nossa série de casos a mortalidade intra-hospitalar observada foi de $66 \%$, coincidindo com dados relatados na Inglaterra por Nolan et al., onde após análise de 28958 casos, durante um período de 10 anos, a mortalidade foi de $71,4 \% .{ }^{(10)}$ No Canadá, em trabalho multicêntrico realizado por Keenan et al., também em UTIs, observou-se mortalidade de $66,5 \%$ quando analisados 2760 pacientes. ${ }^{(13)}$ Nos Estados Unidos, quando analisados os pacientes com mais de 65 anos durante os anos de 1992 a 2005 foi observada mortalidade intra-hospitalar de $81,7 \%$, porém sem diferença estatisticamente significativa no transcorrer do período estudado. ${ }^{(13)}$

Em relação ao local da PCR, apesar de apenas dois pacientes serem originados do bloco cirúrgico, ambos tiveram alta hospitalar, demonstrando uma melhor tendência de recuperação neste grupo de pacientes, coincidindo com dados que demonstraram sobrevida de $43,9 \%$ por Nolan et al., ${ }^{(15)}$ de $34,5 \%$ por Sprung et al., ${ }^{(16)}$ e de $38 \%$ por Girardi et al. ${ }^{(17)}$ Esses melhores resultados podem estar relacionados, talvez, ao fato de que os casos de PCR em ambiente sob monitoramento tenham melhor desenlace.

A implementação de protocolos de tratamento para pacientes com PCR, assim como a abordagem multidisciplinar, demonstraram benefícios no desfecho destes pacientes. ${ }^{(18,19)}$ Nessa série observou-se dados compatíveis com a literatura, ${ }^{(8,9)}$ conseguindo alcançar alguns objetivos tais como o tempo requerido para atingir a temperatura alvo ( 5 horas), o tempo de hipotermia adotado ( 22 horas) e tempo para reaquecimento (9 horas). No que se refere à relação encontrada entre o tempo para atingir hipotermia e óbito, nessa série de dados, paradoxalmente ao esperado, houve mortalidade menor no grupo que atingiu hipotermia mais lentamente $(\mathrm{p}=0,005)$, resultado, talvez atribuído ao número reduzido de pacientes na nossa amostra. Porém mais estudos são necessários para determinar a estratégia terapêutica, já que os dados de ambos os trabalhos não são homogêneos, encontrando média de 8 horas no estudo europeu ${ }^{(9)}$ e 2 horas no australiano ${ }^{(8)}$ para atingir a temperatura alvo.

Apesar destes resultados interessantes é importante salientar várias limitaçóes decorrentes deste estudo, como o seu desenho retrospectivo, o número limitado de pacientes e de tempo de seguimento, a presença de tipos diversos de ritmos de PCR que têm intrinsecamente resultados diferentes quanto à mortalidade e, finalmente, locais diferentes de PCR. Todos estes fatores podem reduzir bastante qualquer sinal eventualmente presente nas análises realizadas.

As principais complicaçóes do uso desta terapêutica são as 
infecçôes, coagulopatias, arritmias e hiperglicemia. ${ }^{(20)}$ Nessa série, observou-se alargamento de RNI e redução na contagem de plaquetas após aplicação de hipotermia, porém não observamos complicaçóes hemorrágicas. Nenhum paciente recebeu hemotransfusão durante ou após a hipotermia (dados não mostrados). Em relação ao aumento de infecçóes observou-se aumento de leucócitos e proteína $\mathrm{C}$ reativa com significância estatística, porém sem determinação de infecção comprovada, após aplicação desta terapêutica.

Em relação às variáveis hemodinâmicas, não existe evidência na literatura sobre quais seriam os valores adequados neste grupo específico de doentes no tocante à pressão arterial média, pressáo venosa central, saturação venosa central, e clareamento de lactato. Assim, os valores considerados adequados seriam aqueles adaptados do early goal-directed therapy. ${ }^{(21,22)}$ Nessa série observou-se um maior requerimento de noradrenalina durante a hipotermia $(0,47 \mathrm{mcg} / \mathrm{kg} / \mathrm{min}$ versus 0,33 $\mathrm{mcg} / \mathrm{kg} / \mathrm{min}$ ), porém sem prejuízo na pressão arterial média e freqüência cardíaca, e notou-se redução no débito cardíaco $(3,2$ e 2,7), tal como observado por Bernard et al. na Austrália. ${ }^{(8)}$ Em relação aos valores de lactato, houve clareamento do mesmo, com diferença estatisticamente significativa entre a admissão e os períodos de hipotermia e após reaquecimento, evidenciando o cumprimento de metas pré-estabelecidas.

O controle glicêmico é assunto controverso. van den Berghe et al. ${ }^{(23)}$, demonstraram redução na mortalidade quando a glicemia era mantida entre 80 e $110 \mathrm{mg} / \mathrm{l}$, porém em publicaçóes recentes, Oksanen et al. ${ }^{(24)}$ e Losert et al., ${ }^{(25)}$ foram encontrados benefícios quando o objetivo era o controle moderado entre 100 e $144 \mathrm{mg} / \mathrm{dl}$. Nesse estudo a glicemia média encontrada foi de $133 \mathrm{mg} / \mathrm{dl}$.

A aplicação desta terapêutica foi facilmente realizada, já que com a infusão de soro a $4^{\circ} \mathrm{C}$ e aplicação de gelo nas dobras cutâneas, alcançam-se os níveis de temperatura desejados. ${ }^{(12,26)} \mathrm{O}$ colchão térmico e bloqueador neuromuscular seriam então adjuvantes que ofereceriam uma maior estabilidade no controle da temperatura, porém a sua falta náo é uma limitação para a aplicação desta técnica.

\section{CONCLUSÁO}

Um protocolo operacional padráo para o tratamento de pacientes reanimados após um episódio de parada car- diorrespiratória resultou em elevada adesão. O principal ponto do protocolo, a aplicação de hipotermia terapêutica mostrou tempos para alcance de hipotermia e reaquecimento compatíveis com os dados de literatura. O resultado aparentemente paradoxal entre o menor tempo para se alcançar a hipotermia e a maior mortalidade deve ser explorado numa série maior de casos. Novas revisóes do protocolo devem ser realizadas a fim de adaptar seus procedimentos à literatura.

\section{ABSTRACT}

Objective: To determine the characteristics of patients undergoing standard institutional protocol for management of resuscitated patients after a cardiac arrest episode, including therapeutic hypothermia.

Methods: This was a retrospective analysis of 26 consecutive patients admitted following cardiac arrest, between January 2007 and November 2008.

Results: All cases underwent therapeutic hypothermia. Average age was 63 years, and the patients were predominantly male. Cardiac arrest event was out-of-hospital in 8 cases, in the emergency room in 3 cases, in the wards in 13 cases and in the operation room in 2 cases. The cardiac arrest rhythm was ventricular fibrillation in seven patients, asystolia in 11, pulseless electrical activity in 5 cases, and was undetermined in 3 patients. The interval between the cardiac arrest and return of spontaneous circulation was 12 minutes $(\mathrm{SD} \pm 5 \mathrm{~min}$ ). The time to reach the target temperature was $5 \pm 4$ hours, the hypothermia time was $22 \pm 6$ hours and time to rewarming $9 \pm 5.9$ hours. Fourteen patients died in the intensive care unit, a 54\% mortality, and three patients died during the in-hospital stay, a $66 \%$ in-hospital mortality. There was statistically significant reduction in hemoglobin $(\mathrm{p}<0.001)$, leukocytes $(\mathrm{p}=0.001)$, platelets $(\mathrm{p}<0.001)$, lactate $(\mathrm{p}<0.001)$ and potassium $(\mathrm{p}=0.009)$, values and increased $\mathrm{C}$ reactive protein $(\mathrm{p}=0.001)$ and INR $(\mathrm{p}=0.004)$ after hypothermia.

Conclusions: The creation of a standard operative protocol for therapeutic hypothermia in post cardiac arrest patients management resulted in a high use of therapeutic hypothermia. The clinical results of this protocol adapted from randomized studies are similar to the literature.

Keywords: Hypothermia; Heart arrest; Intensive care

\section{REFERÊNCIAS}

1. Zheng ZJ, Croft JB, Giles WH, Mensah GA. Sudden cardiac death in the United States, 1989 to 1998. Circulation. 2001;104(18):2158-63.
2. Fredriksson M, Herlitz J, Nichol G. Variation in outcome in studies of out-of-hospital cardiac arrest: a review of studies conforming to the Utstein guidelines. Am J Emerg Med. 2003;21(4):276-81.

3. Nadkarni VM, Larkin GL, Peberdy MA, Carey SM, Kaye 
W, Mancini ME, Nichol G, Lane-Truitt T, Potts J, Ornato JP, Berg RA; National Registry of Cardiopulmonary Resuscitation Investigators. First documented rhythm and clinical outcome from in-hospital cardiac arrest among children and adults. JAMA. 2006;295(1):50-7.

4. Stephenson HE Jr, Reid LC, Hinton JW. Some common denominators in 1200 cases of cardiac arrest. Ann Surg. 1953;137(5):731-44.

5. Safar P. Resuscitation from clinical death: pathophysiologic limits and therapeutic potentials. Crit Care Med. 1988;16(10):923-41.

6. Laurent I, Monchi M, Chiche JD, Joly LM, Spaulding C, Bourgeois B, et al. Reversible myocardial dysfunction in survivors of out-of-hospital cardiac arrest. J Am Coll Cardiol. 2002;40(12):2110-6.

7. Negovsky VA. Postresuscitation disease. Crit Care Med. 1988;16(10):942-6.

8. Bernard SA, Gray TW, Buist MD, Jones BM, Silvester W, Gutteridge G, Smith K. Treatment of comatose survivors of out-of-hospital cardiac arrest with induced hypothermia. N Engl J Med. 2002;346(8):557-63.

9. Hypothermia after Cardiac Arrest Study Group. Mild therapeutic hypothermia to improve the neurologic outcome after cardiac arrest. N Engl J Med. 2002;346(8):549-56. Erratum in: N Engl J Med 2002;346(22):1756.

10. Nolan JP, Morley PT, Vanden Hoek TL, Hickey RW, Kloeck WG, Billi J, Böttiger BW, Morley PT, Nolan JP, Okada K, Reyes C, Shuster M, Steen PA, Weil MH, Wenzel V, Hickey RW, Carli P, Vanden Hoek TL, Atkins D; International Liaison Committee on Resuscitation. Therapeutic hypothermia after cardiac arrest: an advisory statement by the advanced life support task force of the International Liaison Committee on Resuscitation. Circulation. 2003;108(1):118-21.

11. Protocolo Hipotermia Hospital Mater Dei. [citado 2007 Out 4]. Disponível em: <http://www.materdei.com.br/>.

12. Bernard S, Buist M, Monteiro O, Smith K. Induced hypothermia using large volume, ice-cold intravenous fluid in comatose survivors of out-of-hospital cardiac arrest: a preliminary report. Resuscitation. 2003;56(1):9-13.

13. Keenan SP, Dodek P, Martin C, Priestap F, Norena M, Wong $\mathrm{H}$. Variation in length of intensive care unit stay after cardiac arrest: where you are is as important as who you are. Crit Care Med. 2007;35(3):836-41.

14. Ehlenbach WJ, Barnato AE, Curtis RJ, Kreuter W, Koepsell TD, Deyo RA, Stapleton RD. Epidemiologic study of in-hospital cardiopulmonary resuscitation in the elderly. N Engl J Med. 2009;361(1):22-31.

15. Nolan JP, Laver SR, Welch CA, Harrison DA, Gupta V, Rowan K. Outcome following admission to UK intensive care units after cardiac arrest: a secondary analysis of the ICNARC Case Mix Programme Database. Anaesthesia. 2007;62(12):1207-16.

16. Sprung J, Warner ME, Contreras MG, Schroeder DR, Beighley CM, Wilson GA, Warner DO. Predictors of survival following cardiac arrest in patients undergoing noncardiac surgery: a study of 518,294 patients at a tertiary referral center. Anesthesiology. 2003;99(2):259-69.

17. Girardi LN, Barie PS. Improved survival after intraoperative cardiac arrest in noncardiac surgical patients. Arch Surg. 1995;130(1):15-8; discussion 19.

18. Sunde K, Pytte M, Jacobsen D, Mangschau A, Jensen LP, Smedsrud C, et al. Implementation of a standardised treatment protocol for post resuscitation care after out-ofhospital cardiac arrest. Ressuscitation. 2007;73(1):29-39.

19. Oddo M, Schaller MD, Feihl F, Ribordy V, Liaudet L. From evidence to clinical practice: effective implementation of therapeutic hypothermia to improve patient outcome after cardiac arrest. Crit Care Med. 2006;34(7):1865-73.20.

Polderman KH. Application of therapeutic hypothermia in the intensive care unit. Opportunities and pitfalls of a promising treatment modality--Part 2: Practical aspects and side effects. Intensive Care Med. 2004;30(5):757-69.

21. Rivers E, Nguyen B, Havstad S, Ressler J, Muzzin A, Knoblich B, Peterson E, Tomlanovich M; Early Goal-Directed Therapy Collaborative Group. Early goal-directed therapy in the treatment of severe sepsis and septic shock. N Engl J Med. 2001;345(19):1368-77.

22. Gaieski DF, Band RA, Abella BS, Neumar RW, Fuchs BD, Kolansky DM, et al. Early goal-directed hemodynamic optimization combined with therapeutic hypothermia in comatose survivors of out-of-hospital cardiac arrest. Resuscitation. 2009;80(4):418-24.

23. van den Berghe G, Wouters P, Weekers F, Verwaest C, Bruyninckx F, Schetz M, et al. Intensive insulin therapy in the critically ill patients. N Engl J Med. 2001;345(19):135967.

24. Oksanen T, Skrifvars MB, Varpula T, Kuitunen A, Pettilä V, Nurmi J, Castrén M. Strict versus moderate glucose control after resuscitation from ventricular fibrillation. Intensive Care Med. 2007;33(12):2093-100.

25. Losert H, Sterz F, Roine RO, Holzer M, Martens P, Cerchiari E, et al. Strict normoglycaemic blood glucose levels in the therapeutic management of patients within $12 \mathrm{~h}$ after cardiac arrest might not be necessary. Resuscitation. 2008;76(2):214-20.

26. Arrich J; European Resuscitation Council Hypothermia After Cardiac Arrest Registry Study Group. Clinical application of mild therapeutic hypothermia after cardiac arrest. Crit Care Med. 2007;35(4):1041-7. 